\title{
Designing Rubrics to Assess Engineering Design, Professional Practice, and Communication Over Three Years of Study
}

\author{
Natasha Lanziner \\ Master's in Mechanical Engineering \\ Queen's University at Kingston, Ontario \\ natasha.lanziner@queensu.ca
}

\author{
David S. Strong \\ Professor \& NSERC Chair in Design Engineering \\ Queen's University at Kingston, Ontario \\ strongd@queensu.ca
}

\begin{abstract}
When using rubric-based assessment of students' understanding of design process in projectbased courses, it is important to provide specific feedback for major design process elements while avoiding overly prescriptive descriptors [8]. This paper details the development process of a sequence of rubrics used for assessment in successive second, third and fourth year project-based courses. A major consideration in the rubric development process was to ensure the alignment of assessment with course learning outcomes that can be easily mapped to the CEAB graduate attribute accreditation requirements. In the second year course, the rubrics are used to provide students with directed feedback as they learn the basics of engineering design process. The third and fourth year rubrics progress from the second year analytic rubrics by employing elements of holistic assessment. The purpose of evolving these rubrics year over year is to find a balance between the students, learning and development in design process whilst accommodating variation in projects. This ultimately provides students with greater flexibility and encourages responsibility as they progress through their program.
\end{abstract}

Keywords: Rubrics; Graduate Attributes; Assessment; Engineering Design

\section{INTRODUCTION}

Since 2011, Queen's University has been implementing a four-year Engineering Design and Practice Sequence (EDPS) as a core requirement in all programs to enhance students' design, innovation, and professionalism capabilities. Designed as a project based sequence to contribute to the graduate attribute requirements of the Canadian Engineering Accreditation Board, detailed learning outcomes governed the implementation of the EDPS [1]. As a part of the common first year, EDPS I, APSC100 incorporates three modules on problem analysis and modelling, experimentation and measurement, and engineering design. EDPS II APSC200/293, engineering design/engineering communication is a one semester, faculty-wide course comprised of three phases. The first (P0) Phase is an introductory, one-week, design/build/test project aimed mainly at team building and reflective learning. The second (P2) phase is a 5 week, open ended, multidisciplinary project, with parallel teaching and active learning workshops. The third (P2) Phase engages student teams in a six-week discipline-related project, typically with a prototyping or design-of-experiment lab requirement.

Split into APSC200, engineering design and APSC293, engineering communications, EDPS II is implemented faculty-wide. EDPS III includes disciplinespecific courses and/or the elective multidisciplinary course APSC381, Advanced Design for Innovation. EDPS IV includes discipline-specific capstone courses and/or the elective APSC480, Multidisciplinary Industry Engineering Design Project. Together, APSC381 and APSC480 comprise the Multidisciplinary Design Stream (MDS) [3].

The majority of the assessment of engineering design, professional practice, and communication in APSC200/293, APSC381, and APSC480 is completed by assessing engineering design reports. In APSC200/293, students submit a preliminary, interim, and final report for the $\mathrm{P} 1$ project and a proposal and final report for the P2 project. In APSC381, students submit a preliminary, interim, and final report. In APSC480, students submit a series of milestone "briefs", an interim, and final report. In each of the courses, the reports for a given project are successive and build on the previous reports. This paper discusses the development process of a sequence of rubrics to assess engineering design, professional practice, and communication in the engineering design reports submitted for APSC200/293, APSC381, and APSC480. Although EDPS I also incorporates rubric-based assessment, the development process of the EDPS I rubrics is not detailed in this paper.

\section{REVIEW OF LITERATURE}

Prior to developing the sequence of rubrics, a review of assessment literature for engineering design, professional practice, and communication was conducted. The purpose of the literature review was to establish a conception of engineering design and the engineering 
design process, assess perspectives on assessment of engineering design, and to evaluate existing rubric-based assessment methods.

\subsection{Assessment of Engineering Design, Professional Practice, and Communication}

There are multiple approaches to describing the engineering design process in the literature. Generally, it can be defined as a complex process beginning with an analytical phase that involves defining the problem and conducting background research and ending with an implementation phase. There often are multiple iterations of the phases within the process [Lit review]. The design process taught in APSC200/293, APSC381, and APSC480, while unique, is most closely modelled by Dominick et al.'s four-phase process as described in Tools and Tactics of Design [9]. The four phases are Defining the Problem, Formulating Solutions Developing Models and Prototypes, and Presenting and Implementing the Design [9].

In a review of literature on engineering design assessment, three key features of good assessment tools were suggested to be systematic in approach, flexibility of application, and efficient in terms of time and cost [6]. Defined as guidelines that "differentiate between levels of student proficiency," rubrics are commonly used for assessment. Woodhall and Strong conducted a study of an Alternative Assessment Method (AAM) for use in the MDS at Queen's University. The design of the AAM included the design of rubrics to assess engineering design, communication, and professional practice. When designing rubrics, the authors noted the importance of alignment with course learning outcomes [11].

\subsection{The ICE Assessment Approach}

The ICE approach assesses students by measuring their development through three stages of learning. ICE is an acronym for these learning stages, standing for Ideas, Connections, and Extensions. Ideas are demonstrated when students convey the fundamental concepts, including vocabulary and definitions and the basic steps in a process. Connections are made when students demonstrate relationships among the elements in the Ideas stage or between what they have learned and what they already know. Extensions are made when students use their learning in novel ways by finding deeper meanings and applications. When applied to rubrics, the ICE approach uses qualitative descriptors to describe the characteristics of the learning stages [10]. This approach is inherently different than purely quantitative rubrics that often itemize the expected content of the work at different levels. By using qualitative descriptors, instructors can provide students with guidance for how to advance to the next level. Some instructors who have used the ICE approach for rubrics suggest that the inclusion of grade values in the rubric causes students to focus less on the learning descriptors. Because the ICE approach uses measures associated with the learning process, it is useful in assessment of the development of process skills [10].

Prior to the development of the rubric sequence detailed in this paper, the ICE approach was used for assessment in APSC200/293 for its applicability in assessing students' development of design process skills. The ICE approach was also shown to be successful when assessing engineering students' development of professional skills [4]. Students were more capable of grasping the concepts of the ICE learning levels than the nomenclature in Biggs' and Collis' Structure of Observed Learning Outcomes (SOLO) theory. The simple vocabulary in the ICE approach also allowed for easier communication of course learning outcomes and assessment of the outcomes. When using ICE rubrics, the instructors and teaching assistants (TAs) noted they were able to provide more formative feedback to students with fewer frustrations in the grading process [4].

\section{PURPOSE OF THE RUBRICS}

The rubric development process for the EDPS courses was guided by the four main purposes of the sequential rubrics: (i) alignment with the course learning outcomes; (ii) mapping to the graduate attributes; (iii) incorporation of holistic assessment to allow for grade calibration and variation in project types; and (iv) guidance and feedback for students and teaching assistants. During development, the major elements of the rubrics considered were the criteria, descriptors of criteria, weightings of criteria, and levels. Because of previous successes in applications for assessment in engineering design and professional practice courses, the ICE approach to assessment was used in the development process of the rubric sequence.

\subsection{Alignment with Course Learning Outcomes}

For students to improve, it is important that students have an understanding of the learning outcomes [11]. Students are presented with the detailed learning outcomes for APSC200/293, APSC381, and APSC480. Oehler and Walker suggest that when learning how to solve complex, open-ended problems, it is important for students to have knowledge of the assessment methods to guide their learning [5]. It is most important that the sequence of rubrics align with the course learning outcomes to correctly guide student learning and to provide assessment of the desired learning in the course.

The focus of the EDPS courses, as driven by the learning outcomes, is on the process of solving complex problems as opposed to the final solution. In alignment with the outcomes, the main purpose of the sequence of 
rubrics is to assess the process used by students and not the final solution resulting from the process. Assessment methods that focus on the final solution may detract from students' learning of process and techniques for solving open-ended problems [11].

\subsection{Mapping to Graduate Attributes}

Since 2009 when the Canadian Engineering Accreditation Board (CEAB) began requiring assessment of engineering graduate attributes, significant focus has been placed on assessment tools that can be used for both course and graduate attribute assessment. Secondary to its use for course assessment, the rubric sequence is to be used for graduate attribute assessment to show improvement within the courses and over the three-year sequence of courses.

\subsection{Incorporation of Holistic Assessment}

Engineering design is difficult to assess due to the complexity of design thinking, the nonlinear and iterative nature of the design process, and the range of factors that contribute to engineering design. As limiting factors in the assessment process, time and cost do not typically allow for detailed assessment criteria that consider every complexity and factor of the design process [6]. The incorporation of holistic assessment in rubrics can reduce the time and cost of assessment and grading calibration while ensuring the applicability of the rubrics to a range of open-ended engineering design problems.

3.3.1 Grading Calibration. The instruction teams for APSC200/293, APSC381, and APSC480 include a coordinator, course administrator, multiple instructors (one of whom may also be the coordinator), and multiple teaching assistants. Grading calibration is required on two levels: within reports, and within instructors and teaching assistants. The consideration of each detailed criterion combined with a holistic appraisal can improve the time efficiency of grading calibration.

3.3.2 Variation in Projects. There is very little variation in projects in the APSC200/293 P1 Phase, however the variation increases with discipline-specific projects in the P2 Phase. The projects in APSC381 are designed to have relevant applications of the course material and to be appropriate for multidisciplinary teams. There is a maximum of 12 different projects assigned each year (typically 2 teams per project for illustration of different solutions), with some variation in the type of project, typically focusing on product design and/or improvement. The multidisciplinary projects in APSC480, sponsored by industry partners, have the most variation. In the past, projects have included types ranging from conceptual product and system design, to techno-economic analyses, to process improvement. Depending on the nature of the project, the applicability of some of the factors in the engineering design process varies. The incorporation of holistic assessment allows for alignment with course learning outcomes and consideration of the potential variance in applicability.

\subsection{Guidance for Students and TAs}

McMillan described three approaches to assessment as assessment of learning, assessment for learning, and assessment as learning. Assessment for learning and as learning can be considered preferable as they provide immediate feedback to enhance students' motivation. Assessment for learning provides feedback to students whereas assessment as learning fosters student selfmonitoring of learning [7]. An additional purpose of the rubric sequence is to provide feedback to students on their learning while providing students with guidance so they can learn to monitor their own learning.

APSC200/293 and APSC381 commonly employ both undergraduate and graduate TAs and APSC480 employs graduate TAs. The sequence of rubrics also serves to guide TAs in assessment as they become more experienced. TAs feedback comments often suggest that they learn a great deal about design as well as leadership by being involved at the mentoring and assessment level.

\section{THE RUBRIC SEQUENCE DESIGN}

Guided by the learning outcomes and the ICE approach to rubric language and style, three sets of successive rubrics with four grading levels were created. Each set includes rubrics for the major reports in that course. Because the reports are meant to build on one another as students work through their projects, the rubrics also build on one another. The final report rubrics include the criteria in the interim report rubrics, and the interim report rubrics include criteria in the preliminary or proposal report rubrics. This "scaffold" format serves to guide students learning as they work through their projects by establishing a pace and increasing quality level for moving through the design process. In the interim and final report rubrics, the weightings of the rubric criteria are distributed such that the focus shifts to the new criteria. For some criteria, the descriptors and levels are altered within the successive rubrics to accommodate increases in the level of expectation.

A minor modification was made to the ICE assessment approach to define the four levels as Below Minimum Standards $(<50 \%)$, Ideas $(50-65 \%)$, Connections, (65$80 \%$ ), and Extensions (80-100\%). By defining the levels as stages in the learning process, the rubrics incorporate the assessment for learning approach as defined by McMillan. A grade range is provided for each level to remain practical for use in course assessment. 
Following an approach similar to Woodhall and Strong, the criteria in the sequence of rubrics contribute to categories that include design process and technique elements, written communication, and professional practice elements. The design process criteria in the rubrics were partly developed from Dominick et al.'s design process model [11]. To align with the evolving learning outcomes through the courses, there are additional criteria in the APSC381 and APSC480 rubrics, some of which are extracted from typical professional engineering expectations. The criteria were partitioned in such a way that they could be mapped to the graduate attributes. Table 1 provides the rubric categories common to the sequence and the number of criteria contributing to the categories in the final report rubrics for each course.

Table 1: Number of criteria in major rubric categories.

\begin{tabular}{|l|c|c|c|}
\hline Rubric Category & $\mathbf{2 0 0 / 2 9 3}$ & $\mathbf{3 8 1}$ & $\mathbf{4 8 0}$ \\
\hline Communication & 9 & 7 & 7 \\
\hline $\begin{array}{l}\text { Background } \\
\text { Research and } \\
\begin{array}{l}\text { Problem } \\
\text { Definition }\end{array}\end{array}$ & 4 & 5 & 5 \\
\hline Creative Thinking & 1 & 2 & 2 \\
\hline Concept Selection & 1 & 2 & 2 \\
\hline $\begin{array}{l}\text { Concept } \\
\text { Development }\end{array}$ & 1 & 1 & 1 \\
\hline Final Design & 2 & 2 & 4 \\
\hline $\begin{array}{l}\text { Recommendations } \\
\text { and Future Work }\end{array}$ & 2 & 2 & 2 \\
\hline $\begin{array}{l}\text { Design Process } \\
\text { and Integrated }\end{array}$ & 3 & 6 & 6 \\
$\begin{array}{l}\text { Professional } \\
\text { Practice }\end{array}$ & 0 & 1 & 1 \\
\hline $\begin{array}{l}\text { Project } \\
\text { Management }\end{array}$ & & & \\
\hline
\end{tabular}

Although the rubrics in the sequence share common categories of criteria and levels, the design of the APSC200/293 rubrics is distinctly different from the APSC381 and APSC480 rubrics. Descriptors of each of the four levels for each criterion are included in the APSC200/293 rubrics. As well, weightings are assigned to each criterion. The APSC381 and APSC480 rubrics provide less granularity, with descriptors provided for the main criteria but not for the levels within each criterion. This allows for a wide variety of project topics while still describing competency in each assessment criterion. Weightings are assigned to groupings of criteria instead of to each criterion. The transition in descriptors from the APSC200/293 rubrics to the APSC381 and APSC480 rubrics require students to think critically when assessing their learning levels. By assigning weightings to groupings of criteria instead of individual criterion, holistic assessment methods are further incorporated. An example of the evolutions in descriptors, criteria, and weightings is shown in the Appendix for the problem definition category in the final report rubrics.

\subsection{APSC200/293}

As the second course in the EDPS, APSC200/293 covers the "fuzzy front end" of design process tools, techniques and professional practice. The APSC200/293 detailed descriptors of the ICE levels incorporate the assessment as learning approach discussed by McMillan. The descriptors of the ICE levels characterize the stages of learning for each criterion, allowing students to use the rubrics as a guide for their learning. Particular care was taken in establishing the descriptors. As suggested by Rasul, an attempt was made to avoid overly prescriptive descriptions [8]. The descriptors characterize the qualities of the given level for each criterion without fully detailing how to achieve that level. The structure of the language is also designed to deter the students from using the rubrics as a checklist, although achieving this in reality is an extremely challenging task. Minimal grade values were included in the rubrics to ensure that students focus on the descriptors. The grade ranges for the levels are provided in the column headings and a section is provided for writing the overall report grades. To provide further guidance to students, each of the levels (BICE) are divided into a lower, central, and upper range for feedback to students. Graders highlight the appropriate section (e.g. I+ or E-) on a spreadsheet, but do not assign a grade value; that is calculated by a formula applied equally to all grade spreadsheets. The additional division of the levels helps to indicate, for instance, if students are at the Connections level, but are approaching the Extensions level.

Although EDPS II is comprised of two courses, each report assessed using the rubrics contributes to both APSC200 and APSC293. The engineering design and communication elements were combined into single rubrics for each of the reports, giving two grades to be calculated from each rubric.

\subsection{APSC381 and APSC480}

APSC381 and APSC480 cover more advanced concepts and techniques for engineering design and professional practice, and go further into the process for refinement and optimization of solutions. At a minimum, students enrolled in these courses have successfully completed EDPS I and II. Upon enrolling in APSC381 and APSC480 students have been previously exposed to the application of the ICE assessment approach in the APSC200/293 rubric set and a similar approach in APSC 100 , and thus are expected to have a conceptual understanding of the Below Minimum Standards, Ideas, 
Connections, and Extensions levels. Guidance is provided to students in the form of descriptions of each criterion instead of descriptors of each level for each criterion. Although the criteria are grouped together for weightings to calculate the overall report grades, feedback is provided to students for each criterion using the four levels. The evaluation of each criterion using the levels also allows for mapping to the learning outcomes and graduate attributes.

There are slight differences in the content of the APSC381 and APSC480 rubric sets to accommodate differences in learning outcomes and expectations in projects. The differences in the final report rubrics are in the descriptions of the engineering science criterion, which is within the overall design process grouping of criteria, and the descriptions of criteria in the concept development and final solution criteria groupings.

\subsection{Grade Calculation Methods}

The APSC200/293 rubric set uses a different method for calculating the overall report grades than the APSC381 and APSC480 rubric sets. To calculate the APSC200/293 overall grades, a percentage is assigned to the each of the lower, central, and upper ranges of each level. The overall grades result from the weighted sum of the percentages for each criterion.

Percentages were not assigned to the four levels in the APSC381 and APSC480 rubrics. Instead, the APSC381 and APSC480 rubrics use the upper and lower bounds of the grade ranges to calculate an upper and lower bound for the overall grade. Similar to the APSC200/293 calculation method, the upper and lower grade bounds are calculated as a weighted sum of the criteria. However, weightings are applied to groupings of criteria as opposed to single criteria, so a percentage is required for each criteria grouping. To simplify the calculations of the upper and lower grade bounds, the upper and lower grade bounds for the level of the criteria in a grouping were averaged to give upper and lower percentages for the grouping to be used in a weighted sum. The APSC381 and APSC480 rubric structure does not require an equally weighted average for calculating percentages for the groupings, so depending on variation in projects, a weighted average can be applied. Instead of giving a single overall grade, an upper and lower grade bound and average grade are calculated. Holistic assessment is then incorporated to determine where in the overall grade range the report actually sits. The average of the upper and lower bounds is the starting point for the holistic approach. In practice, the final grades for all projects are discussed and calibrated by the instructions team, with at least 2 readers per report.

\section{CONCLUSIONS AND FUTURE WORK}

At this time, the APSC200/293 rubric set has been implemented for two academic years, while the APSC381 and APSC480 rubric sets have been implemented for one academic year. A full assessment has not yet been completed to determine the success of the rubric sequence. The consideration of learning outcomes when developing the criteria, descriptions, and level descriptors ensured that each set of rubrics is aligned with their respective course learning outcomes. The breakdown of the criteria in each rubric and collection of data for each criterion ensure that the rubrics can be used for mapping to the graduate attributes. However, further investigation is needed to determine the use of the rubric sequence for graduate attribute assessment. The structure of the rubrics in the sequence incorporates a degree of holistic grading, especially for APSC381 and APSC480.

An exploration of how TAs and instructors use the rubrics, and particularly the holistic capability, would be beneficial to further improve on the design of the sequence. The time efficiency and reliability of the two grade calculation methods could be compared to determine the optimal method. Assessment of the impact of these rubrics based on outcome quality and student learning may lead to further evolution of this assessment methodology.

\section{Acknowledgements}

The authors gratefully acknowledge supportive funding from the NSERC Chair in Design Engineering. We would like to acknowledge and thank Gillian Woodruff, Georgina Rainsford, and the past APSC381 and APSC480 teaching assistants and students for their valuable contributions and insights during the development process of the rubrics.

\section{References}

[1] Brian M. Frank, David S. Strong, Rick Sellens, and Lynann Clapham, "Progress with the professional spine: A four-year Engineering Design and Practice Sequence," Australasian Journal of Engineering Education 19(1), pp. 63, 2013.

[2] Clive L. Dym, Alice M. Agogino, Ozgur, Eris, Daniel D. Frey, and Larry J. Leifer, "Engineering design thinking, teaching, and learning," Journal of Engineering Education, pp. 103-210, 2005.

[3] David S. Strong, “An approach for improving design and innovation skills in engineering education: The multidisciplinary design stream," International Journal of Engineering Education 28(2), pp. 339, 2012. 
[4] David S. Strong and S. Fostaty Young. "Effectively assessing professional engineering skills," in Proc. The Fourth CDEN Design Conf., (Winnipeg, MN; 2007), 2007.

[5] Deric Oehlers and David Walker. "Assessment of deep learning ability for problem solvers," International Journal of Engineering Education 22(6), pp. 1261, 2006.

[6] Iman Moazzen, Terry Hansen, Mariel Miller, Peter Wild, Allyson Hadwin, and LillAnne Jackson, "Literature review on engineering design assessment tools," in Proc. CEEA Canadian Engineering Education Conf., CEEA13 (Montreal, QC; 17-20 June 2013), 2013.

[7] J. H. McMillan, Classroom Assessment, Pearson Education, United States of America, 2007.
[8] M. S. Rasul, "Employability skills assessment tool development," International Education Studies 5(5), 2012.

[9] P. G. Dominick, J. T. Demel, W. . Lawbaugh, R. J. Freuler, G. L. Kinzel, and E. Fromm, Tools and Tactics of Design. Wiley, New York, 2001.

[10] S. Fostaty Young and R. J. Wilson, Assessment \& Learning: The Ice Approach. Portage \& Main Press, Winnipeg, 2000.

[11] Thomas F.C. Woodhall and David S. Strong, "Implementing a Rubric-based Assessment Scheme into the Multidisciplinary Design Stream at Queen's University," in Proc. CEEA Canadian Engineering Education Conf., CEEA08 (Halifax, NS; 27-29 July 2008), 2008.

\section{APPENDIX}

Table 2: Problem definition criteria in the APSC200/293 final report rubric.

\begin{tabular}{|c|c|c|c|c|}
\hline Rubric Element & B & I & C & E \\
\hline Stakeholder Needs & $\begin{array}{c}\text { Missing or trivial } \\
\text { identification and } \\
\text { consideration of } \\
\text { stakeholder needs. }\end{array}$ & $\begin{array}{c}\text { Significant stakeholders } \\
\text { are identified with } \\
\text { nominal description. }\end{array}$ & $\begin{array}{c}\text { All relevant stakeholders } \\
\text { are identified and their } \\
\text { needs are well defined. }\end{array}$ & $\begin{array}{c}\text { All relevant stakeholders are } \\
\text { identified with clear descriptions, } \\
\text { relevance, and impact of their needs. }\end{array}$ \\
\hline Problem Statement & $\begin{array}{l}\text { Missing or incomplete } \\
\text { statement that leaves } \\
\text { ambiguity in the } \\
\text { problem. }\end{array}$ & $\begin{array}{c}\text { Cursory description } \\
\text { outlines key ideas, but } \\
\text { leaves some uncertainty. }\end{array}$ & $\begin{array}{c}\text { Clear and complete } \\
\text { statement that scopes the } \\
\text { problem and does not } \\
\text { predetermine the solution. }\end{array}$ & $\begin{array}{c}\text { Clear, insightful, and focused } \\
\text { statement elegantly distills the } \\
\text { problem in concise language. }\end{array}$ \\
\hline $\begin{array}{c}\text { Design Criteria and } \\
\text { Specifications }\end{array}$ & $\begin{array}{l}\text { Missing, trivial, vague } \\
\text { or unrelated criteria or } \\
\text { constraints. }\end{array}$ & $\begin{array}{c}\text { Simplistic criteria and } \\
\text { constraints with some } \\
\text { relevance to stakeholder } \\
\text { needs. }\end{array}$ & $\begin{array}{c}\text { Specific and measurable } \\
\text { criteria and constraints } \\
\text { developed from research } \\
\text { and stakeholder needs. }\end{array}$ & $\begin{array}{c}\text { Comprehensive, detailed and precise } \\
\text { criteria and constraints logically } \\
\text { developed from analysis of research } \\
\text { and stakeholder needs. }\end{array}$ \\
\hline
\end{tabular}

Table 3: Problem definition criteria in the APSC381 final report rubric.

\begin{tabular}{|c|c|c|c|c|c|}
\hline Report Element & Subsection & \multicolumn{4}{|c|}{ Level } \\
\hline $\begin{array}{l}\text { Stakeholder Needs } \\
\text { Analysis }\end{array}$ & - Determination, assessment, relevance of stakeholders and their needs & B & I & $\mathrm{C}$ & $\mathrm{E}$ \\
\hline Problem Statement & $\begin{array}{l}\text { - Clarity and concision } \\
\text { - Inclusion of key “problem' details, captured in a brief summary }\end{array}$ & B & I & $\mathrm{C}$ & E \\
\hline $\begin{array}{l}\text { Constraints and } \\
\text { Assumptions }\end{array}$ & $\begin{array}{l}\text { - Project scope is well defined with clear constraints and assumptions } \\
\text { - Logic, reasoning, and justification suitable for project topic }\end{array}$ & B & I & $\mathrm{C}$ & E \\
\hline $\begin{array}{l}\text { Design Criteria and } \\
\text { Specifications }\end{array}$ & $\begin{array}{l}\text { - Clear description of functional, aesthetic, and other requirements } \\
\text { - Comprehensiveness, detail, and precision appropriate to project topic } \\
\text { - Reader clearly understands outcomes required for successful solution }\end{array}$ & B & I & $\mathrm{C}$ & E \\
\hline
\end{tabular}

Table 4: Problem definition criteria in the APSC480 final report rubric.

\begin{tabular}{|c|c|c|c|c|c|}
\hline Report Element & Subsection & \multicolumn{4}{|c|}{ Level } \\
\hline $\begin{array}{c}\text { Stakeholder } \\
\text { Needs Analysis }\end{array}$ & - Determination and assessment of stakeholder needs & B & I & $\mathrm{C}$ & E \\
\hline $\begin{array}{l}\text { Problem } \\
\text { Statement }\end{array}$ & $\begin{array}{l}\text { - Clarity and concision of key project details } \\
\text { - Establishment of a clear scope and objectives, concisely stated }\end{array}$ & B & I & C & E \\
\hline $\begin{array}{c}\text { Constraints and } \\
\text { Assumptions }\end{array}$ & $\begin{array}{l}\text { - Logic, reasoning, and justification } \\
\text { - Assessment of validity of assumptions }\end{array}$ & B & I & C & E \\
\hline $\begin{array}{c}\text { Design Criteria } \\
\text { and } \\
\text { Specifications }\end{array}$ & $\begin{array}{l}\text { - Clear description of functional, aesthetic, and other requirements } \\
\text { - Value proposition in terms of monetary or non-monetary value to the client (e.g. market, productivity, cost } \\
\text { reduction, customer recognition, etc.) } \\
\text { - Comprehensiveness, detail, and precision appropriate to project topic } \\
\text { - Reader clearly understands outcomes required for successful solution }\end{array}$ & B & I & C & E \\
\hline
\end{tabular}

